\title{
Reações e sentimentos da família frente à internação do recém-nascido na unidade neonatal
}

\author{
Family reactions and feelings about newborn hospitalization in the neonatal unit \\ Reacciones y sentimientos de la familia sobre la hospitalización del recién nacido en la \\ unidad neonatal
}

Caroline Passos Arruda ${ }^{1 \star}$, Giovana Calcagno Gomes ${ }^{1}$ Laís Farias Juliano ${ }^{1}$, Pâmela Kath de Oliveira Nornberg ${ }^{1}$, Stella Minasi de Oliveira ${ }^{1}$ e Manoela Cunha Nicoletti ${ }^{1}$.

\section{RESUMO}

Objetivo: conhecer as reações e sentimentos da família frente à internação do recém-nascido na Unidade de Terapia Intensiva Neonatal. Método: pesquisa qualitativa realizada em Unidade Neonatal no sul do Brasil em 2018. Participaram 12 familiares. A coleta de dados foi realizada por meio de entrevistas e os dados submetidos à Análise de Conteúdo. Resultados: A aceitação da internação foi difícil e acompanhada de medo, angústia, ansiedade, mas também de fé e esperança. Procuraram permanecer o máximo de tempo com o recém-nascido. A licença gestante favoreceu o acompanhamento do mesmo. Mães que permaneceram internadas tiveram o contato diário e a criação do vínculo com o neonato favorecidos. O tempo que passaram no setor foi aproveitado para desempenhar cuidados e para a amamentação. Conclusão: Profissionais que atuam em unidades neonatais devem implementar estratégias de apoio para auxiliar as famílias no cuidado ao neonato no setor e no enfrentamento da situação vivenciada.

Palavras-chave: Recém-nascido, Unidades de Terapia Intensiva Neonatal, Pais, Cuidados de Enfermagem, Enfermagem neonatal.

\section{ABSTRACT}

Objective: to know the reactions and feelings of the family regarding the hospitalization of the newborn in the Neonatal Intensive Care Unit. Method: qualitative research conducted in a Neonatal Unit in southern Brazil in 2018. Twelve family members participated. Data collection was performed through interviews and data submitted to Content Analysis. Results: The acceptance of hospitalization was difficult and accompanied by fear, anguish, anxiety, but also faith and hope. They sought to stay as long as possible with the newborn. The maternity leave favored the monitoring of it. Mothers who were hospitalized had daily contact and bonding with the newborn. The time spent in the sector was taken to care and breastfeeding. Conclusion: Professionals working in neonatal units should implement support strategies to assist families in caring for the newborn in the sector and coping with the situation experienced.

Key words: Newborn, Neonatal Intensive Care Units, Parents, Nursing Care, Neonatal Nursing.

\section{RESUMEN}

Objetivo: conocer las reacciones y sentimientos de la familia con respecto a la hospitalización del recién nacido en la Unidad de Cuidados Intensivos Neonatales. Método: investigación cualitativa realizada en una Unidad Neonatal en el sur de Brasil en 2018. Participaron doce familiares. La recopilación de datos se realizó a través de entrevistas y datos enviados a análisis de contenido. Resultados: La aceptación de la

${ }^{1}$ Universidade Federal do Rio Grande (FURG), Rio Grande/RS. *E-mail: carolparruda@gmail.com 
hospitalización fue difícil y estuvo acompañada de miedo, angustia, ansiedad, pero también fe y esperanza. Intentaron quedarse el mayor tiempo posible con el recién nacido. El permiso de maternidad favoreció su seguimiento. Las madres que fueron hospitalizadas tenían contacto diario y lazos con el recién nacido. El tiempo que pasó en el sector fue dedicado al cuidado y la lactancia. Conclusión: Los profesionales que trabajan en unidades neonatales deben implementar estrategias de apoyo para ayudar a las familias a cuidar al recién nacido en el sector y hacer frente a la situación experimentada.

Palabras clave: Recién Nacido, Unidades de Cuidados Intensivos Neonatales, Padres, Cuidados de Enfermería, Enfermería neonatal.

\section{INTRODUÇÃO}

Um dos momentos mais intensos e significativos da vida é o nascimento de um filho, pois está associado à renovação, significando o início de um novo ciclo no âmbito familiar (SOUZA JP e PILEGGI-CASTRO C, 2014). O parto é um momento de mudanças consideráveis para a identidade da mulher. Seu significado é construído e reconstruído de acordo com as experiências vivenciadas por ela. Conforme foi previsto no prénatal as gestantes esperam que seu parto ocorra sem intercorrências e que o bebê nasça saudável e sem complicações (TOSTES NA e SEIDL EMF, 2016).

A necessidade de um recém-nascido (RN) receber cuidados assistenciais em uma Unidade de Tratamento Intensivo Neonatal (UTIN), logo após seu nascimento, pode estar relacionada a múltiplos fatores. Os agravos sofridos nesse setor podem deixar marcas em sua vida (COSTA ALRR; ARAUJO JE; LIMA JWO; COSTA FS, 2014). O recém-nascido ( $R N)$ vivencia um ambiente com sons altos, luzes constantes e grande número de pessoas. Além disso, é submetido a procedimentos dolorosos. A família depara-se com um RN pequeno e frágil (CARTAXO LS, et al., 2014).

A separação do RN da família, o medo do diagnóstico, do desconhecido, do ambiente hospitalar e a dúvida quanto ao presente e ao futuro pode desestruturar a família. Esse cenário pode gerar sentimentos de insegurança, medo e incerteza o que afeta o equilíbrio familiar (VERONEZ M, et al., 2017). Existem inúmeros fatores que podem estar relacionados à necessidade de internação de um RN em uma Unidade de Tratamento Intensivo Neonatal (UTIN) imediatamente após o seu nascimento. Dentre estes destacam-se fatores biológicos, socioeconômicos, de profissionais de saúde até institucionais (LIMA SS, et al., 2015).

A UTIN é destinada à assistência a RN admitidos entre 0 e 28 dias. É uma área de alta complexidade destinada à internação de pacientes com patologias graves. Estes demandam cuidados contínuos por profissionais especializados e aparelhos específicos que são necessários para sua monitorização, diagnóstico e terapia. Sendo estruturada com o objetivo de melhorar o estado de saúde e diminuir a mortalidade (ANVISA, 2010).

A tecnologia utilizada na UTIN está cada vez mais desenvolvida e avançada. A neonatologia, reconhecida como especialidade, possibilitou a compreensão das particularidades dos neonatos, além do desenvolvimento de equipamentos e medicamentos específicos para sua clientela (BRITES TAM, et al., 2015).

A maioria das vezes as famílias não estão preparadas para lidar com rotina da UTIN, o que se torna um obstáculo diário gerando sentimentos indesejáveis e desencantadores. "Esses sentimentos são evidenciados a cada dia, com a chegada dos pais ao domicílio e a impossibilidade de trazer o neonato consigo, podendo aflorar a sensação de angústia e vazio (MAIA JMA, et al., 2015).

As visitas realizadas pelas mães ao RN na UTIN são momentos almejados. Porém, a despedida ao final das visitas é dolorosa, visto que a família anseia pelo dia da alta hospitalar. Este sentimento é constituído por um estado de constante ansiedade à espera de informações que signifiquem a evolução clínica do bebê e a proximidade da alta (VERONEZ M, et al., 2017).

A equipe de enfermagem deve desenvolver uma observação minuciosa acerca da interação entre o RN e a família. Compete ao enfermeiro o aperfeiçoamento acerca da sensibilidade de intuir o estado psicológico 
dos familiares. Deste modo, saber identificar como eles tem se adaptado a esta situação, como é o relacionamento com o neonato e se a família necessita de algum tipo de apoio/suporte para lidar com a internação do RN (ROLIM K, et al., 2017).

A dificuldade de enfrentamento da internação do RN na UTIN pode levar a família a um quadro de depressão, ansiedade, fadiga e distúrbios do sono, comprometendo o estabelecimento do vínculo com o RN, interferindo no seu desenvolvimento após a alta (BUSSE M; STROMGREN K; THORNGATE L; THOMAS KA, 2013). Considerando as repercussões negativas da internação do RN na UTIN para a família é importante conhecer como esses tem reagido. Nesse sentido objetivou-se conhecer as reações e sentimentos vivenciados pela família frente à necessidade da internação do RN na Unidade de Terapia Intensiva Neonatal.

\section{MÉTODOS}

Realizou-se um estudo exploratório, descritivo com abordagem qualitativa. Teve como contexto a UTIN de um Hospital Brasileiro. O hospital é considerado de grande porte e realiza atendimentos a gestantes de alto risco. A UTIN é dividida em: uma unidade intensiva, uma unidade para cuidados intermediários e uma unidade canguru. Presta assistência apenas a pacientes usuários do Sistema Único de Saúde.

Participaram familiares que atenderam ao critério de inclusão: ser familiar/acompanhante de RN internado na UTIN e estar presente diariamente acompanhando o RN e ter dezoito anos ou mais. Foram excluídos familiares que acompanharam o RN na UTIN apenas nos horários de visita. Depois de orientados acerca dos objetivos e metodologia do estudo, os que aceitaram participar assinaram o Termo de Consentimento Livre e Esclarecido.

A coleta de dados deu-se por meio de entrevista semiestruturada, onde o pesquisador proporciona uma liberdade de comunicação aos participantes entrevistados. Algumas perguntas realizadas na entrevista foram: Como se deu o recebimento da necessidade de internação do teu filho na UTIN? Como está sendo o enfrentamento/organização da internação do teu filho na UTIN? Que sentimentos a família apresentou frente à internação do RN na UTIN? Que dificuldades estão enfrentando para acompanhar a internação do RN na UTIN?. A análise dos dados deu-se pela Análise de Conteúdo operacionalizada em três etapas: Pré-análise; exploração do material e tratamento dos resultados, inferência e interpretação (BARDIN L, 2009).

Respeitaram-se os preceitos da resolução 466/2012 do Conselho Nacional de Saúde, no que tange aos aspectos éticos para a pesquisa com seres humanos. O projeto foi aprovado pelo Comitê de Ética sob número 142/2018. Os participantes foram identificados pela letra $F$ seguida do número da entrevistas.

\section{RESULTADOS}

Participaram do estudo 12 familiares cuidadores, sendo 10 mães e dois pais. Suas idades variaram entre 18 e 38 anos, sendo a média de idades de 28 anos. Uma participante era analfabeta, quatro possuíam ensino fundamental incompleto, um ensino médio incompleto, dois ensino médio completo e quatro ensino superior completo. Quanto ao local de moradia 11 residiam no município em que a UTIN se localizava e uma habita outro município próximo. Os participantes possuíam entre um e seis filhos, sendo a média de filhos 2,5. Os motivos de internação do RN na UTIN foram prematuridade (4), aspiração de mecônio (4), malformação pulmonar (3), malformação cardíaca (2), crise convulsiva (1) e sepse neonatal (1).

\section{Impacto da necessidade de internação do RN na UTIN para a família}

Em relação ao planejamento familiar, cinco participantes referiram que a gravidez foi planejada, que queriam ter um filho e que já estariam tentando há algum tempo.

Acho que sim. Sim foi. (F10)

Sim, foi planejada. Nós já queríamos ter um filho. (F3)

Foi, eu e meu marido já estávamos tentando. Então veio ele. (F7)

REAS/EJCH | Vol.11(15) | e1444 | DOI: https://doi.org/10.25248/reas.e1444.2019 Página 3 de $\mathbf{9}$ 
Relataram que a gravidez não foi planejada sete participantes do estudo. Alguns referiram que mesmo não esperando a gravidez neste momento ela aconteceu e a partir do diagnóstico a criança passou a ser desejada.

Não queria mais um agora, mas já que veio. (F4)

Não era né, mas agora passou a ser. (F6)

Outros participantes referiram que a gestação não era planejada e que ocorreu devido a falha do método contraceptivo.

\author{
Não, nem pensar, mas os métodos falharam. (F5) \\ Não, não foi. A camisinha estourou ai eu tive ele. Já que veio vou ter que criar né. \\ (F1)
}

Todos os participantes do estudo mencionaram que as mães apresentaram intercorrências durante 0 período gestacional.

Dentre elas citaram diabetes, hipertensão arterial, sangramento, perda do tampão mucoso e descolamento prematuro da placenta.

Ela fez as consultas de pré-natal. Eu levava, mas foi só três. Ela tirou sangue, fez uns exames e não tinha dado nada. Aí a médica novinha ficou empurrando para frente a data do parto, até que ela passou mal e eu trouxe ela aqui. Aqui falaram que ela tinha diabetes, mas pelo menos foi só isso. (F2)

Duas participantes relatam ter apresentado hipertensão arterial durante a gestação e outra foi informada que estaria hipertensa no momento do parto.

Eu fiz o pré-natal até a 27 semana. Com 26 semanas a médica me disse que eu estava com pressão alta, Com 27 semanas comecei a sentir umas dores e vim para o hospital. Cheguei aqui e já ganhei ele. (F8)

Eu fiz o pré-natal foi tranquilo até a hora do parto. Tive as dores e vim para o hospital. Na hora de ganhar a médica me disse que eu era hipertensa e que o bebê já tinha passado do tempo, então tive que fazer uma cesariana. (F10)

Três participantes referiram ter apresentado sangramento. Uma a partir da $26^{\circ}$ semana de gravidez, outra na $28^{\circ}$ semana e uma a partir da $33^{\circ}$ semana.

Fizeram repouso absoluto, mas, no entanto, apresentaram dilatação do colo do útero e entraram em trabalho de parto.

Fui às consultas de pré-natal completo, mas foi particular. Mas com 28 semanas eu tive um sangramento, então fiz repouso absoluto. Depois com 29/30 semanas eu perdi o tampão mucoso, aí eu continuei em repouso. Aí na 33 semana entrei em trabalho de parto. (F3)

Eu tive um sangramento, mas eu não sei ao certo em qual semana foi. Depois eu descobri que eu não estava contando certo as semanas, mas acho que foi com 33/34 semanas.(F4)

Alguns participantes afirmaram que a intercorrência apresentada foi descolamento de placenta. Duas mães a partir da $33^{\circ}$ semana e uma mãe a partir da $35^{\circ}$ semana, sendo necessária a realização da cesariana.

Mas agora com 33 semanas teve o descolamento da placenta e então foi feita a cesárea de emergência. (F6)

Com 35 semanas eu tive ruptura de placenta. Então me trouxeram aqui para o hospital nesta cidade. (F12) 
Alguns pais referiram terem sido informados da necessidade de internação do RN na UTIN logo após o parto devido suas condições clínicas. Foram informados que o RN apresentou disfunção respiratória, aspiração de mecônio e/ou nascido antes do tempo.

Foi depois que eu ganhei ele, ali no Centro Obstétrico. Me falaram que ele não se adaptou a respiração aqui fora e que também ele tinha engolido um pouco de fezes, mas que foi mais pela respiração que ele precisava ir para a UTI. (F11)

No trabalho de parto já conversaram comigo sobre a hipótese dele nascer e de precisar ir para a UTI Neo. A enfermeira veio e falou comigo sobre o assunto. (F3)

Outros participantes expuseram que após o parto no CO o RN foi levado direto para a UTIN. Uma delas inclusive referiu ter pensado que o $\mathrm{RN}$ havia sido levado para a realização de exames, levando um baque e ficando triste ao saber da internação na UTIN.

A primeira que foi a gêmea dois eu nem vi. Já levaram da barriga direto para a UTI. (F5)

Foi quando eu estava na sala de recuperação que vieram me contar. Achei que só tinham levado ele para fazer exames, mas quando ela me disse, foi um baque, fiquei triste. (F10)

Quatro participantes referiram que após o nascimento o $\mathrm{RN}$ foi levado para a maternidade junto com a mãe e que devido suas condições clínicas nas primeiras horas de vida necessitaram a internação na UTIN.

A gêmea um só veio para cá porque na hora não tinha leito na UTI, mas aí ela parou de mamar, então chamei a enfermeira para ver ela e em seguida conseguiram um leito para ela lá na UTI junto com a outra. (F5)

Foi quando eu já estava na maternidade com ele. Eles fizeram uns exames nele. Aí descobriram a infecção. Então a enfermeira falou que tinha que levar para a UTI para tratar. (F4)

Uma das participantes residente em outro município foi informada que devido à prematuridade o RN teria que ser transferido e internado na UTIN.

Foi quando eu estava na minha cidade, antes de vir para cá. Me falaram que ele tinha que vir para a UTI para ganhar peso e fazer um tratamento para melhorar porque ele nasceu antes da data. Aí como lá na minha cidade não tem recurso viemos para cá. (F12)

\section{Organização da família frente à internação do RN na UTIN}

Verificou-se que após a internação do RN a família se organiza para acompanhar o neonato no setor, permanecendo com o mesmo o maior tempo possível.

Referiram que o acesso livre à unidade favorece a organização da família para permanecer no setor junto com a criança de acordo com a sua disponibilidade.

Eu estou conseguindo ir ali ver ele porque mãe tem livre acesso. É só chegar que eu consigo entrar e ver ele. (F12)

Agora eu estou conseguindo ir ver ele seguido. Já fui duas vezes. Consigo entrar ali quando quero. Então está bom. (F8)

Uma das mães referiu que por conta da gestação ela já não estaria mais trabalhando e que a licença gestante favorece o acompanhamento do RN na UTIN.

Agora eu estou inteiramente para ele. Então eu já não estava mais trabalhando desde que eu tive a primeira intercorrência.. Então estou sempre aqui para ele. (F3) 
Em algumas situações a mãe permanece internada na maternidade. Assim, verificou-se que esse fato pode ser um facilitador para a visita da mãe ao RN na UTIN, mas, também, são mães que se apresentam clinicamente instáveis, tendo dificuldade de permanecer por um longo período.

Por enquanto que estou internada também estou conseguindo ir ali toda hora, ficar um pouco com elas. Por enquanto estou conseguindo acompanhar elas. (F5)

Agora que eu consegui ir ali ver ele, porque antes eu não estava conseguindo me levantar. Estava me sentindo mal, tonta. Eu fiz cesárea. Acho que era por causa disso. Mas já fui ali, já vi ele hoje. (F9)

Outra forma de organização da família para acompanhar o RN internado é se dividir entre o pai, a mãe, a comadre e a avó para que sempre tenha alguém junto com a criança no setor. Tal fato mostra a necessidade de uma reorganização familiar.

Assim, eu e a minha comadre estamos ficando aqui e cuidando dele. Mas agora ela teve que ir para casa. Então, eu estou aqui. Passo todo o tempo que posso aqui cuidando dele. (F4)

Eu estou me organizando assim, indo ali ver ele. Ai divido com o pai dele, uma hora vou eu, outra hora ele vai. Por enquanto estamos nos organizando assim, está indo. (F11)

Verificou-se que o tempo em que passam é aproveitado para observar os cuidados realizados com o neonato, como, por exemplo, o banho e com a retirada de leite no banco de leite.

Assisto o banho delas e também tiro o leite no banco de leite para elas. (F5)

\section{Sentimentos apresentados pela família frente à internação do RN na UTIN}

Referiram que a situação pela qual estão passando é muito ruim. Sentem saudades do RN e relatam que acreditavam estar tudo bem, não cogitando a possibilidade da internação do neonato.

Sinto saudades dele, queria ter ele do meu lado. Não achei que isso pudesse acontecer. Estava tudo tão bem. (F10)

Olha está sendo ruim. Não sabia que ia acontecer isso, assim. Era para ser como os outros, nasceu vai para casa com a gente, não ficar aqui.(F2)

Consideram a situação pela qual estão passando muito difícil, necessitando que sejam fortes, pois, não gostariam que o filho ficasse sozinho no hospital.

Apresentam uma mistura de sentimentos, angústia, medo, ansiedade e esperança.

Não queria estar passando por isso. É difícil para toda a família. É muita ansiedade, não quero que ele fique sozinho desamparado. Quero ter ele nos meus braços comigo. (F12)

É angústia, medo, esperança, tudo junto e misturado. Porque hoje eu ganho, então meu coração está apertado. Tu esperas nove meses e depois nem consegues ficar junto com ele. (F11)

Referiram como sentimento a tristeza pelo fato do RN não estar com eles.

Tristes por não terem tido tempo de se preparar para a situação vivenciada, de chegarem em casa e verem o berço vazio, de quererem pegar no colo e dar carinho e não poder.

Assim, sentem-se frustrados de não poderem estar junto com o bebê.

Sinto tristeza por não ter elas aqui com nós. A gente fica triste [choro]. A gente olha para o bercinho, louca para pegar no colo, dar amor e dar carinho [choro]. (F5) 
É triste, porque, depois que passa o primeiro momento aí tu chegas em casa sem ele, olhas as roupinhas, olhas as outras mães indo embora com o filho no colo ai tu tem que deixar. É bem frustrante [choro]. (F3)

Consideram a situação pela qual estão passando horrível e sentem-se mal de ir para casa deixando o RN no hospital. Inclusive, um dos participantes referiu ser a segunda vez que está passando pela situação.

É horrível, queria ir para casa com ele. Não queria ter que deixar ele aqui sozinho. Me sinto mal não quero nem ir para casa agora à noite, mas a minha sogra disse que ele vai ficar bem aqui. (F4)

É um inferno, é horrível. Estou passando isso pela segunda vez. O meu segundo filho também teve que ir para a UTI, mas o caso dele foi mais grave. (F11)

Outros sentimentos referidos foram o medo, a angústia e a ansiedade. Justificaram tal sentimento pela insegurança a respeito do quadro clínico do $\mathrm{RN}$.

Avaliam que o mesmo é instável e que o RN pode tanto melhorar quanto piorar durante seu período de internação na UTIN.

Acho que sinto medo, angústia, ansiedade também. Tudo junto! (F4)

Tristeza, medo, insegurança, angústia. Um pouco de cada coisa. (F6)

Eu sinto medo porque é uma relação instável. Ele pode tanto ter uma melhora quanto ele pode ter uma piora. (F7)

No entanto, apresentam esperança na melhora do RN e na sua possível alta. Alguns utilizam a fé em Deus como base para sua esperança e acreditam que tudo ficará bem no final.

Ah, eu estou com esperança. (F9)

Mas tenho esperança dele sair de lá logo. (F1)

Esperança. Mas se deus quiser ele vai sair dessa. Estou rezando para que isso aconteça logo. (F10)

Tenho fé em Deus. Elas vão se recuperar logo. (F5)

\section{DISCUSSÃO}

No presente estudo todas as mães apresentaram intercorrências na gravidez. As principais complicações obstétricas são doenças hipertensivas, infecções, hemorragias e diabetes. Estas também foram classificadas como as causas mais frequentes de mortalidade materna no Brasil (BRASIL, 2015). Um dos motivos da necessidade de internação do neonato na UTIN ocorre pela dificuldade de adaptação à vida extrauterina, o que pode ser decorrer da sua imaturidade fisiológica e do seu processo terapêutico.

Foram informados da necessidade da internação logo após o parto devido ao quadro clínico do RN. Estudos apontam que as principais causas de internação na UTIN são as doenças respiratórias e a prematuridade, afetando a maioria dos RN. Estas causas são resultantes da grande vulnerabilidade neonatal a infecções e da imaturidade do sistema respiratório (DAMIAN, et al., 2016).

A internação do recém-nascido na UTIN pode ser considerada um acontecimento gerador de diversas emoções para os familiares. Assim, é necessário conhecer os sentimentos apresentados pelos pais, para poder implementar orientações e estratégias que os auxiliem a suportar esse período difícil da separação do seu RN (KEGLER JJ, et al., 2019).

Quanto aos sentimentos apresentados pela família frente à internação do RN internado na UTIN referiram ser muito difícil, triste, horrível, ter medo, angústia e ansiedade. No entanto, apresentaram fé e esperança, conseguindo controlar-se e manter-se tranquilo. Mesmo reconhecendo a importância da UTIN para o 
tratamento e evolução do neonato estudo aponta que a internação desperta nos familiares sentimentos como medo, angustia e tristeza (MELO RA, et al., 2016).

A fé em Deus também foi descrita como um mecanismo que auxilia o enfrentamento das situações difíceis. Assim, a fé possibilitou que as mães cultivassem um sentimento de esperança, suporte e conforto para lidar com o cotidiano da internação na UTIN (BRAGA PP e SENA RR, 2017).

Sentimentos de frustação e tristeza frente a separação fragilizam o ambiente familiar e os pais. A hospitalização torna-se uma experiência desafiadora, visto que, ocasiona uma barreira física e psicológica, dificultando a interação e a criação do vínculo. Além disso, a incubadora atrapalha os pais no contato pele-apele com o filho (VERONEZ M, et al., 2017).

Estudo aponta que a presença/permanência dos familiares na UTIN é considerada um fator de segurança para os pais. Além disso, a presença dos pais no ambiente proporciona aos RNs um bem-estar pelo aconchego da família (CUNHA ALC, et al., 2014).

A licença maternidade favorece a permanência da mãe junto ao RN na UTIN. Contudo, já os pais contam com uma licença menor o que pode desfavorece sua permanência junto ao RN (MARQUES SS e OLIVEIRA MAC, 2017).

Além disso, algumas mães permanecem internadas o que favorece o contato diário e a criação do vínculo com o RN na UTIN. O vínculo materno-fetal está associado a uma ligação já existente desde a vida intrauterina, sendo fortificado através do contato pele-a-pele no pós-parto (RONCALLO CP, et al., 2015).

Outra forma de organização é compartilhar o acompanhamento do RN com mais membros da família, assim os pais contam com auxílio para que o neonato esteja sempre acompanhado. Os membros da família auxiliam os pais no cuidado ao neonato, além de passarem tranquilidade e segurança. Também é uma oportunidade de desenvolver o vínculo através da aproximação familiar, visto que, o contato com outros membros é mais restrito (PEGO CO e BARROS MMA, 2017).

\section{CONCLUSÃO}

Através da pesquisa foi possível concluir que a aceitação da internação foi difícil e acompanhada de medo, angústia, ansiedade, mas também de fé e esperança. Os pais procuraram permanecer o máximo de tempo com o recém-nascido e período que estes passaram no setor foi aproveitado para desempenhar cuidados e para a amamentação. As reações e sentimentos identificados apontam para a necessidade de minimizar seu sofrimento. Assim, acredita-se que profissionais atuantes em unidades neonatais elaborem estratégias de apoio efetivas de maneira a auxiliar as famílias no cuidado ao RN internado no setor, de forma harmônica para enfrentamento menos traumático da situação vivenciada.

\section{REFERÊNCIAS}

1. Agência Nacional de Vigilância Sanitária. Resolução RDC No 7, de 24 de fevereiro de 2010. Brasília, DF: Diário Oficial da União, 2010.

2. BARDIN L. Análise de Conteúdo. 70a ed. Lisboa: Almedina, 2009.

3. BRAGA PP, SENA RR de. Devir cuidadora de prematuro e os dispositivos constituintes da continuidade da atenção pós-alta. Texto contexto - enferm. [Internet], 2017; 26(3):e3070016.

4. BRASIL. Ministério da Saúde. Secretaria de Vigilância em Saúde. Saúde Brasil 2014: uma análise da situação de saúde e das causas externas. Brasília: Ministério da Saúde, 2015.

5. BRITES TAM, et al. Percepção das mães quanto ao atendimento, estado de saúde e prognóstico de seus filhos internados em UTI Neonatal. Revista Médica do Paraná, 2015; 73(2):25-31.

6. BUSSE $M$ et al. Parents' responses to stress in the neonatal intensive care unit. Crit Care Nurse [Internet]. 2013; 33(4):52-9.

7. CARTAXO LS et al. Vivência de mães na unidade de terapia intensiva neonatal. Rev Enferm UERJ [Internet]. 2014; 22(4):551-7. 
8. COSTA ALRR et al. Fatores de risco materno associados a necessidade de unidade de terapia intensiva neonatal. Rev. Bras. Ginecol. Obstet. [Internet]. 2014; 36(1): 29-34.

9. Cunha ALC et al. Visita aberta em uma unidade de terapia intensiva neonatal: percepção dos visitantes. Rev Rene. [Internet]. 2014;15(1):45-51.

10. DAMIAN A et al. Perfil de neonatos internados em Unidade de Tratamento Intensivo Neonatal: estudo transversal. Arquivos de Ciências da Saúde [Internet]. 2016; 23(2):100-5.

11. KEGLER JJ et al. Estresse em pais de recém-nascidos em uma Unidade de Terapia Intensiva Neonatal. Esc. Anna Nery [Internet]. 2019; 23(1): e20180178.

12. LIMA SS et al. Aspectos clínicos de recém-nascidos admitidos em Unidade de Terapia Intensiva de hospital de referencia da Região Norte do Brasil. ABCS Health Sci [Internet]. 2015; 40(2):62-8.

13. MAIA JMA et al. A relação da família com crianças hospitalizadas na Unidade de Terapia Intensiva Neonatal com a equipe de enfermagem. Rev Enferm Contemp [Internet]. 2014;3(2):154-64.

14. MARQUES SS, OLIVEIRA MAC. Direito Fundamental à Licença - Paternidade e Masculinidades no Estado Democrático de Direito. Revista Culturas Jurídicas [Internet]. 2017; 4(9):222-48.

15. MELO RA et al. Sentimentos de mães de recém-nascidos internados em uma unidade intensiva neonatal. Rev Multidisc Psic. 2016;10(32):88-103.

16. PEGO CO, BARROS MMA. Unidade de Terapia Intensiva Pediátrica: expectativas e Sentimentos dos Pais da Criança Gravemente Enferma. Revista Brasileira Ciências da Saúde [Internet]. 2017; 21(1):11-20.

17. ROLIM K et al. O uso de tecnologia leve na promoção da relação enfermeira e pais na UTI Neonatal. CIAIQ [Internet]. 2017; 2:684-93.

18. RONCALLO CP et al. Vínculo materno fetal: implicaciones em El desarrollo psicológico y propuesta de intervención em atención temprana. Revista Escritos de Psicologia [Internet]. 2015; 8(2):14-23.

19. SOUZA JP, PILEGGI-CASTRO C. Sobre o parto e o nascer: a importância da prevenção quaternária. Cad. Saúde Pública [Internet]. 2014; 30 (Suppl1): S11-S13.

20. TOSTES NA, SEIDL EMF. Expectativas de gestantes sobre o parto e suas percepções acerca da preparação para o parto. Temas psicol. [Internet]. 2016; 24(2): 681-693.

21. VERONEZ M et al. Vivência de mães de bebês prematuros do nascimento a alta: notas de diários de campo. Rev. Gaúcha Enferm. [Internet]. 2017; 38(2): e60911. 